\title{
Effect of Multidomain Disease Presentations on Patients With Psoriatic Arthritis in the Corrona Psoriatic Arthritis/ Spondyloarthritis Registry
}

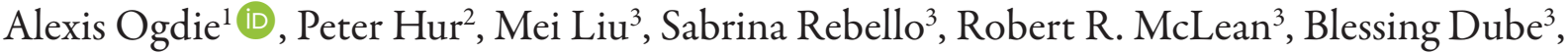 \\ Meghan Glynn ${ }^{3}$, and Philip J. Mease ${ }^{4}$
}

\begin{abstract}
Objective. To compare disease characteristics, quality of life (QOL), and work productivity of patients with psoriatic arthritis (PsA) who had multidomain vs single-domain presentations.

Methods. Adults with PsA enrolled in the Corrona PsA/Spondyloarthritis Registry (March 2013-August 2018) were included. Six PsA disease domains were evaluated: enthesitis, dactylitis, peripheral arthritis (PA), nail psoriasis, axial disease, and skin disease. Patients were classified as having multidomain ( $\geq 2$ domains) or single-domain disease presentations; biologic initiators were characterized separately. Linear regression models evaluated the association of multidomain presentations with disease characteristics, QOL, and work productivity vs single-domain presentations.

Results. Of 2617 patients with PsA, 1698 (64.9\%) had multidomain presentations, 617 (23.6\%) had single-domain presentations, and 302 (11.5\%) had no active disease features. Of 354 biologic initiators, 289 (81.6\%) had multidomain presentations, 45 (12.7\%) had single-domain presentations, and 20 (5.6\%) had no active disease features. Overall, the most common single-domain and multidomain presentations, respectively, were skin disease (12.7\%) and PA + skin disease (11.7\%). Multidomain presenters were more likely to have fibromyalgia, depression, anxiety, and prior biologic use than single-domain presenters. Multidomain presentations were associated with significantly worse patient and physician global assessments of disease activity, pain, and fatigue; Health Assessment Questionnaire-Disability Index and EuroQol 5-dimension scores; and work productivity at enrollment.

Conclusion. In this US real-world cohort, most patients had multidomain disease presentations, which was associated with worse disease activity, QOL, and work productivity measures. This study highlights the heterogeneity of PsA and the importance of assessing all PsA domains for optimizing disease management.
\end{abstract}

Key Indexing Terms: epidemiology, GRAPPA, inflammation, psoriatic arthritis, registries

Psoriatic arthritis (PsA) is a heterogeneous, systemic inflammatory rheumatic disease with articular and extraarticular manifestations, including axial skeleton disorders, nail and skin conditions, peripheral joint inflammation, enthesitis, and/ or dactylitis ${ }^{1}$. These manifestations can emerge either alone or in combination, resulting in pain, impaired physical function, and poor quality of life (QOL) $)^{2,3,4}$. PsA is frequently associated with psoriasis; $10-40 \%$ of patients with psoriasis may go on to

\footnotetext{
This study was sponsored by Corrona, LLC. Corrona, LLC, has been supported through contracted subscriptions in the last 2 years by AbbVie, Amgen, Boebringer Ingelheim, Bristol Myers Squibb, Celgene, Crescendo, Eli Lilly and Company, Genentech, Gilead, GSK, Horizon Pharma USA, Janssen, Momenta Pharmaceuticals, Novartis, Pfizer, Roche, and UCB. The design and conduct of the study were a collaborative effort between Corrona, LLC, and Novartis, and financial support for the study was provided by Novartis. Novartis participated in the interpretation of data and review and approval of the manuscript. Support for third-party writing assistance for this manuscript, furnished by Kheng Bekdache, PhD, of Health Interactions Inc., was provided by Novartis Pharmaceuticals Corporation, East Hanover, NJ.

${ }^{1} A$. Ogdie, MD, MCSE, Perelman School of Medicine at the University of Pennsylvania, Philadelphia, Pennsylvania; ${ }^{2}$ P. Hur, PharmD, MBA, Novartis Pharmaceuticals Corporation, East Hanover, New Jersey; ${ }^{3}$ M. Liu, PhD, S. Rebello, MPH, R.R. McLean, DSc, MPH, B. Dube, MPH, M. Glynn, MS, CPH, Corrona, LLC, Waltham, Massachusetts; ${ }^{4}$ P.J. Mease, MD, MACR, Swedish Medical Center/Providence St. Joseph Health and University of Washington, Seattle, Washington, USA.
}

$A O$ has received consulting fees from AbbVie, Amgen, Bristol Myers Squibb, Celgene, Lilly, Novartis, Pfizer, and Takeda, and has received grant support from the National Institutes of Health/National Institute of Arthritis and Musculoskeletal and Skin Diseases, Rheumatology Research Foundation, National Psoriasis Foundation, Pfizer, and Novartis. PH is an employee of Novartis Pharmaceuticals Corporation. SR, RRM, and BD are employees of Corrona, $L L C$. ML and $M G$ were employees of Corrona, $L L C$, at the time of this analysis. PJM has received research grants from AbbVie, Amgen, Bristol Myers Squibb, Janssen, Lilly, Novartis, Pfizer, Sun, and UCB; consulting fees from AbbVie, Amgen, Boebringer Ingelheim, Bristol Myers Squibb, Celgene, Galapagos, Gilead, Janssen, Lilly, Novartis, Pfizer, Sun, and UCB; and speakers bureau fees from AbbVie, Amgen, Bristol Myers Squibb, Celgene, Genentech, Janssen, Lilly, Novartis, Pfizer, and UCB.

Address correspondence to Dr. A. Ogdie, Hospital of the University of Pennsylvania, 3400 Spruce Street, 5 White Building, Philadelphia, PA 19104,USA.Email:alexis.ogdie@uphs.upenn.edu.

Full Release Article. For details see Reprints and Permissions at jrheum.org. Accepted for publication September 9, 2020. 
develop PsA ${ }^{4,5,6}$. The Group for Research and Assessment of Psoriasis and Psoriatic Arthritis (GRAPPA) and the European League Against Rheumatism have developed guidelines for the treatment and management of patients with PsA based on the different clinical manifestations of $\mathrm{PsA}^{7,8,9}$. A PsA core set of domains for measurement in clinical trials and longitudinal observational studies was originally developed in $2006^{10}$ and updated in 2016 by GRAPPA with recommendations from the Outcome Measures in Rheumatology ${ }^{2}$ to incorporate both physician and patient perspectives ${ }^{3}$. The development of an updated PsA core domain set emphasizes the need to measure a wide spectrum of disease manifestations to optimize management of patients with PsA.

PsA domain presentations are often heterogeneous, ranging from single to multiple disease domains ${ }^{11}$. Because the frequency, type, and severity of the disease domains may affect treatment effectiveness and disease outcomes, careful consideration of the disease domain by the clinician may be critical for choosing the appropriate treatment ${ }^{12}$. There are limited real-world studies examining disease domain presentation among patients with PsA; our group has previously characterized patients with PsA affected in a single domain ${ }^{13,14}$. The objective of this study was to describe the epidemiology and patterns of disease domain presentations among patients with PsA and investigate the association of PsA symptoms, QOL, and work productivity among patients with PsA with single-domain vs multidomain disease presentation.

\section{MATERIALS AND METHODS}

Data source. The Corrona Psoriatic Arthritis/Spondyloarthritis (PsA/SpA) Registry is a large, independent, prospective, observational cohort of patients diagnosed with PsA or SpA by a rheumatologist. Patients were recruited from 44 private and academic practice sites across 27 states in the United States, with 52 participating rheumatologists. As of June 30, 2019, data on approximately 3939 patients with PsA/SpA had been collected. The Corrona PsA/SpA Registry includes information on 15,806 patient visits, with approximately 8423 patient-years of follow-up, with a mean time of patient follow-up of 2.9 years (median $2.4 \mathrm{yrs}$ ). The study protocol was approved by a central institutional review board (IRB; New England Independent Review board, NEIRB No. 120160070) for private practice sites and the local governing IRBs of participating academic sites. All research was conducted in compliance with the Declaration of Helsinki of 1964 and all later amendments. All registry subjects were required to provide written informed consent and authorization prior to participating.

Study design and population. This was a cross-sectional observational study that included all adult patients with PsA enrolled in the Corrona PsA/SpA Registry between March 21, 2013, and August 1, 2018. Patients were required to meet the Classification Criteria for Psoriatic Arthritis at registry enrollment ${ }^{15}$. Data were collected at the enrollment visit and included patient demographics, clinical characteristics, disease activity, QOL, and Work Productivity and Activity Impairment (WPAI) measures.

Study assessments. Patients were categorized into 6 disease domains at their enrollment visit based on the following definitions (patients may have been categorized into > 1 domain):

Enthesitis: patients with Spondyloarthritis Research Consortium of Canada enthesitis count $>0$

Dactylitis: patients with peripheral dactylitis count $>0$

Peripheral arthritis (PA): patients with tender joint counts and/or swollen joint counts $>0$

Nail psoriasis: patients with global nail psoriasis severity visual analog scale $($ VAS $)>0$
Axial disease: patients with a physician-reported presence of spinal involvement at time of registry enrollment, based on clinical judgment of features thought to be representative of active inflammatory spondylitis and/or radiographs or magnetic resonance imaging (MRI) showing sacroiliitis such as sacroiliitis grade $>2$ bilaterally or grades 3-4 unilaterally by radiograph, active (acute) inflammation on MRI highly suggestive of $\mathrm{SpA}$-associated sacroiliitis, definite radiographic sacroiliitis according to modified New York criteria, and other evidence of sacroiliitis on imaging

- Skin disease: patients with $>0 \%$ body surface area affected by psoriasis.

The most common active domain presentations were characterized and the number of patients presenting with single vs multiple disease domains were examined. For each disease domain, the frequency of patients who presented with $\geq 1$ active disease domain was calculated. Additionally, those who initiated a biologic at enrollment were examined separately for comparison. Patients who did not meet the definition for any active disease domain were classified as having no active disease features.

Statistical analysis. Categorical variables were summarized using frequency counts and percentages. Continuous variables were summarized using the number of observations, mean, and SD. Within the total PsA cohort and the biologic initiator cohort, baseline demographics, clinical characteristics, and patient-reported outcome measures were compared between the multidomain and single-domain cohorts using chi-square tests or Fisher exact tests for categorical variables and $t$-tests or Wilcoxon rank-sum tests for continuous variables. The most common mutually exclusive disease presentations among all patients with PsA and those who initiated biologics were summarized using frequency counts and percentages. Separate univariable and multivariable linear regression models evaluated the association of the presence of multidomain presentations with selected PsA disease characteristics, QOL, and work productivity measures relative to single-domain presentations among the total PsA population. Multivariable models were adjusted for age, sex, race, BMI, disease duration, current and prior biologic, conventional synthetic disease-modifying antirheumatic drug (csDMARD), and prednisone use. All statistical analyses were performed using Stata, version 15 (StataCorp) ${ }^{16}$.

\section{RESULTS}

Epidemiology of all patients at enrollment. A total of 2617 patients with PsA were enrolled in the Corrona PsA/SpA Registry at the time of this analysis, of whom 354 (13.5\%) initiated a biologic at registry enrollment (Supplementary Table 1, available with the online version of this article). Of the 2617 patients in the overall population, 2315 (88.5\%) had $\geq 1$ active domain presentation at enrollment; 1814 (69.3\%) presented with skin disease, 1523 (58.2\%) with PA, 1042 (39.8\%) with nail psoriasis, 539 (20.6\%) with enthesitis, 319 (12.2\%) with axial disease, and $235(9.0 \%)$ with dactylitis. Of the 354 patients who initiated a biologic at enrollment, 334 (94.4\%) had $\geq 1$ active domain presentation at enrollment; $273(77.1 \%)$ presented with PA, 267 (75.4\%) with skin disease, 159 (44.9\%) with nail psoriasis, 115 (32.5\%) with enthesitis, 70 (19.8\%) with dactylitis, and 64 (18.1\%) with axial disease. The frequency of other active disease domains present at enrollment in combination with each active disease domain among all patients with PsA who had $\geq 1$ active domain $(\mathrm{n}=2315)$ and among biologic initiators who had $\geq 1$ active domain $(\mathrm{n}=334)$ is shown in Figure $1 \mathrm{~A}$ and Figure $1 \mathrm{~B}$, respectively.

Regarding the frequency of active PsA domain presentations by number of domains affected among all patients with PsA, 1698 patients (64.9\%) had $\geq 2$ domain presentations, 617 
(23.6\%) had single-domain presentations, and 302 (11.5\%) had no active presentations (Figure $2 \mathrm{~A}$ ). The most common disease presentations were skin disease only (12.7\%), PA + skin disease (11.7\%), and PA + nail psoriasis + skin disease (10.3\%; Figure $2 \mathrm{~B})$. Overall, $6.8 \%$ of patients were reported to have PA only. Among all 354 biologic initiators, 289 (81.6\%) had $\geq 2$ domain presentations, 45 (12.7\%) had single-domain presentations, and 20 (5.6\%) had no active presentations (Figure 2C). The most common disease presentations were $\mathrm{PA}+$ nail psoriasis + skin disease (11.6\%), PA + skin disease (11.3\%), enthesitis +
$\mathrm{PA}+$ nail psoriasis + skin disease (8.8\%), and enthesitis + PA + skin disease (5.9\%; Figure 2D). A total of $5.9 \%$ of biologic initiators were reported to present with PA only.

Characterization of single-domain and multidomain disease presentations: demographics and disease characteristics at enrollment. Among all patients with PsA manifesting single-domain vs multidomain presentations, the mean (SD) ages were 54.5 (12.9) vs 53.5 (13.2) years, and $51.5 \%$ vs $53.7 \%$ were women, respectively. Patients with multidomain presentations were more likely to have psoriasis, nail psoriasis, depression, fibromyalgia,

\begin{tabular}{|c|c|c|c|c|c|c|}
\hline \multirow{2}{*}{$\begin{array}{l}\text { Concurrent } \\
\text { Active Domains, } \\
\text { n (\%) }\end{array}$} & \multicolumn{6}{|c|}{ Active PsA Disease Domain } \\
\hline & $\begin{array}{l}\text { Enthesitis } \\
(n=539)\end{array}$ & $\begin{array}{l}\text { Dactylitis } \\
(n=235)\end{array}$ & $\begin{array}{c}\text { PA } \\
(n=1523)\end{array}$ & $\begin{array}{l}\text { Nail Psoriasis } \\
\qquad(n=1042)\end{array}$ & $\begin{array}{l}\text { Axial Disease } \\
\qquad(n=319)\end{array}$ & $\begin{array}{l}\text { Skin Disease } \\
\quad(n=1814)\end{array}$ \\
\hline Enthesitis & $539(100)$ & $66(28.1)$ & $465(30.5)$ & $285(27.4)$ & $110(34.5)$ & $423(23.3)$ \\
\hline Dactylitis & $66(12.2)$ & $235(100)$ & $210(13.8)$ & $125(12.0)$ & $26(8.2)$ & $195(10.7)$ \\
\hline PA & $465(86.3)$ & $210(89.4)$ & $1523(100)$ & $699(67.1)$ & $214(67.1)$ & $1150(63.4)$ \\
\hline Nail Psoriasis & $285(52.9)$ & $125(53.2)$ & $699(45.9)$ & $1042(100)$ & $160(50.2)$ & $848(46.7)$ \\
\hline Axial Disease & $110(20.4)$ & $26(11.1)$ & $214(14.1)$ & $160(15.4)$ & $319(100)$ & $233(12.8)$ \\
\hline Skin Disease & $423(78.5)$ & $195(83.0)$ & $1150(75.5)$ & $848(81.4)$ & $233(73.0)$ & $1814(100)$ \\
\hline
\end{tabular}

\begin{tabular}{|l|c|c|c|c|c|c|}
\hline \multirow{2}{*}{$\begin{array}{l}\text { Concurrent } \\
\text { Active Domains, } \\
\mathrm{n}(\%)\end{array}$} & \multicolumn{5}{|c|}{ Active PsA Disease Domain } \\
\cline { 2 - 7 } & $\begin{array}{c}\text { Enthesitis } \\
(\mathrm{n}=115)\end{array}$ & $\begin{array}{c}\text { Dactylitis } \\
(\mathrm{n}=70)\end{array}$ & $\begin{array}{c}\text { PA } \\
(\mathrm{n}=273)\end{array}$ & $\begin{array}{c}\text { Nail Psoriasis } \\
(\mathrm{n}=159)\end{array}$ & $\begin{array}{c}\text { Axial Disease } \\
(\mathrm{n}=64)\end{array}$ & $\begin{array}{c}\text { Skin Disease } \\
(\mathrm{n}=267)\end{array}$ \\
\hline Enthesitis & $115(100)$ & $25(35.7)$ & $104(38.1)$ & $62(39.0)$ & $27(42.2)$ & $95(35.6)$ \\
\hline Dactylitis & $25(21.7)$ & $70(100)$ & $64(23.4)$ & $33(20.8)$ & $10(15.6)$ & $57(21.3)$ \\
\hline PA & $104(90.4)$ & $64(91.4)$ & $273(100)$ & $131(82.4)$ & $48(75.0)$ & $217(81.3)$ \\
\hline Nail Psoriasis & $62(53.9)$ & $33(47.1)$ & $131(48.0)$ & $159(100)$ & $33(51.6)$ & $141(52.8)$ \\
\hline Axial Disease & $27(23.5)$ & $10(14.3)$ & $48(17.6)$ & $33(20.8)$ & $64(100)$ & $50(18.7)$ \\
\hline Skin Disease & $95(82.6)$ & $57(81.4)$ & $217(79.5)$ & $141(88.7)$ & $50(78.1)$ & $267(100)$ \\
\hline
\end{tabular}

Figure 1. Frequency of other concurrently active disease domains in patients presenting with each active disease domain among (A) all patients with PsA and $\geq 1$ affected domain $(n=2315)$ and $(B)$ biologic initiators with $\geq 1$ affected domain $(n=334)$ at registry enrollment. Heat map represents the frequency of any 2 domain combinations by the range of blue shades, with the darkest blue specifying the highest frequency and the lightest blue specifying the lowest frequency of combinations. PA: peripheral arthritis; PsA: psoriatic arthritis. 
A All Patients With PsA $(\mathrm{N}=2617) \quad$ B
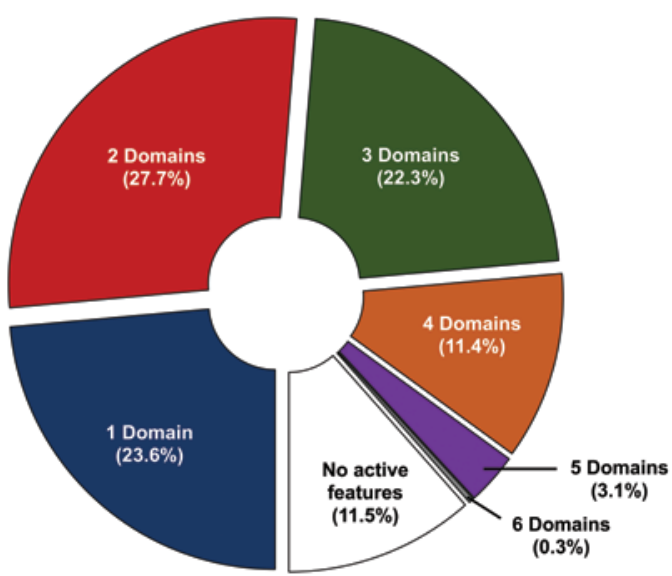

1 Domain $(n=617)$

2 Domains $(n=726)$

C

Biologic Initiators $(\mathrm{N}=\mathbf{3 5 4}$ )

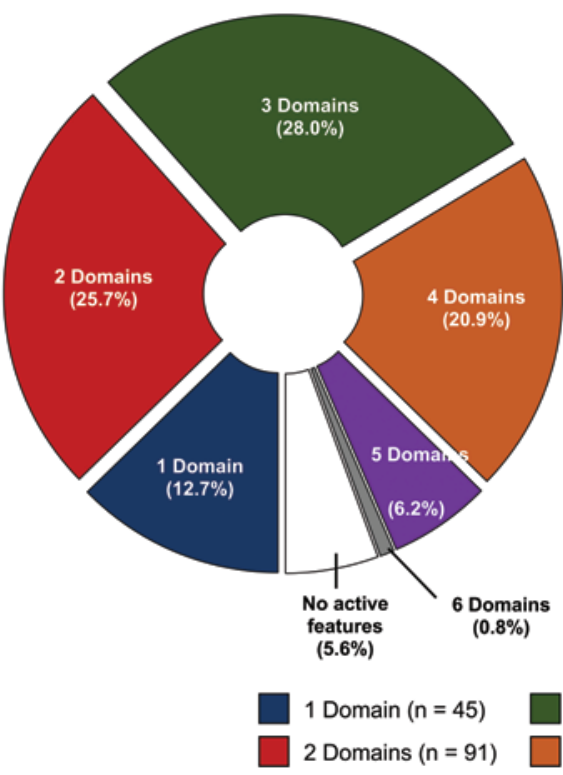

3 Domains $(n=583)$

4 Domains $(n=299)$
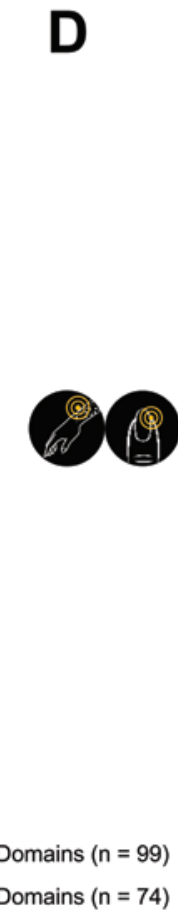

P)
All Patients With PsA (N = 2617)
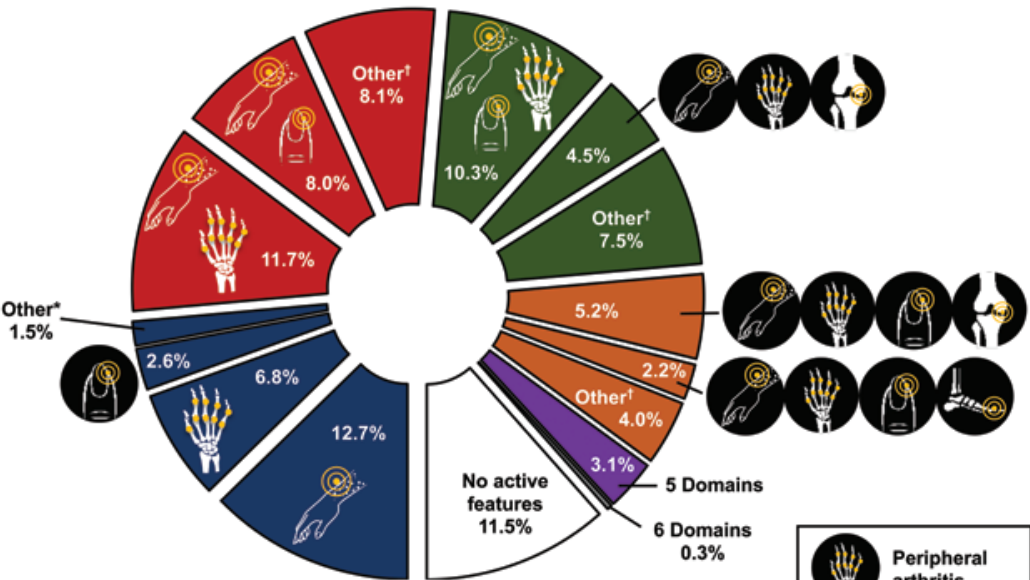

5 Domains $(n=82)$

6 Domains $(n=8)$

No active features $(n=302)$

No active

features 6 Domains

$0.3 \%$
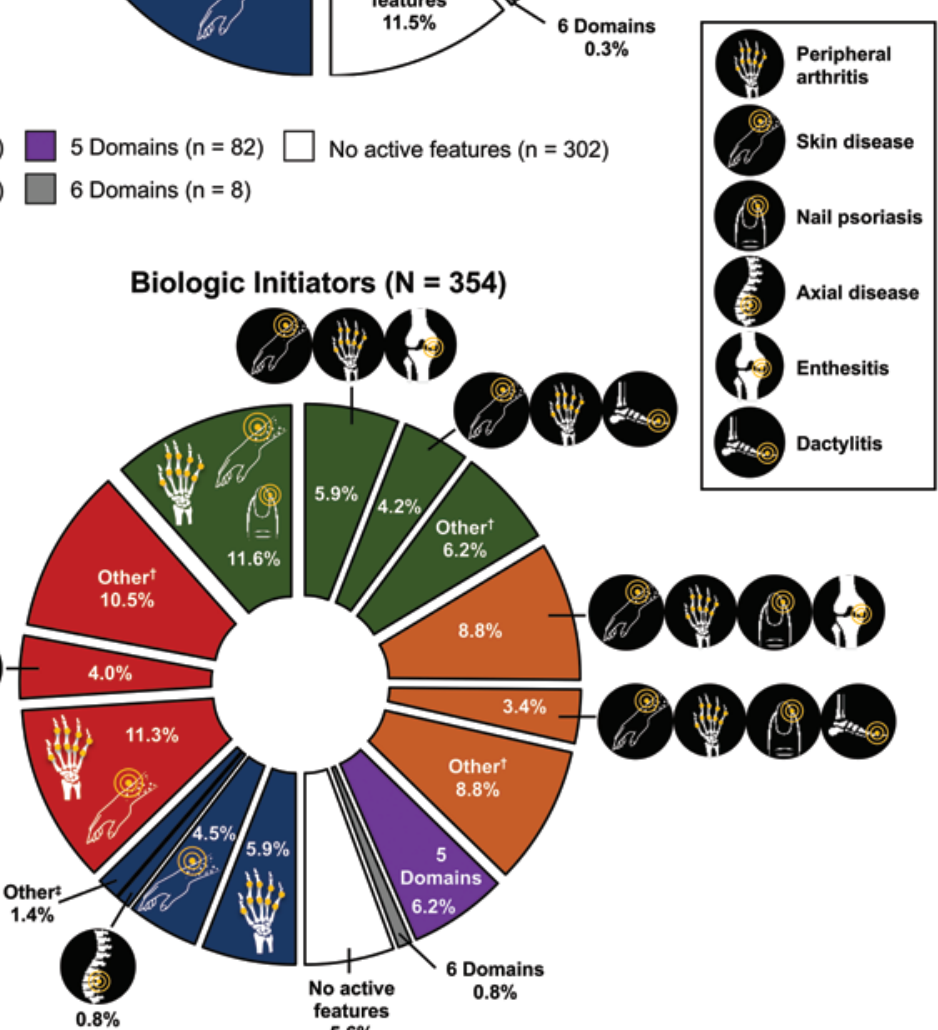

5 Domains $(n=22)$

6 Domains $(n=3)$

Figure 2. Frequency of most common active PsA domain presentations by number of domains affected among (A, B) all patients with PsA ( $\mathrm{n}=2617)$ and (C, D) biologic initiators $(\mathrm{n}=354)$. " "Other" presentations include axial disease, enthesitis, and dactylitis. " "Other" presentations include all other combinations of $\geq 2$ domains not shown in the figure. "Other" presentations include nail psoriasis, enthesitis, and dactylitis. PsA: psoriatic arthritis.

anxiety, and a history of biologic use than were patients with single-domain presentations (all $P<0.05$; Table 1 ).

Among biologic initiators with single-domain vs multidomain presentations, the mean (SD) ages were 52.5 (12.7) vs 51.5 (13.2) years, and $47.7 \%$ and $52.2 \%$ were women, respectively. Biologic initiators with multidomain presentations were more likely to have nail psoriasis, depression, psoriasis, and current csDMARD use than were biologic initiators with single-domain presentations (all $P<0.05$; Table 1).
Disease activity, QOL, and work productivity at enrollment. As expected, patients with multidomain presentations had worse overall disease activity compared with those with single-domain presentations in unadjusted comparisons both for patients with PsA overall and for biologic initiators (Table 2). Additionally, multidomain presenters were more likely to have worse physical function as measured by Health Assessment QuestionnaireDisability Index (HAQ-DI), QOL as measured by the EuroQol 5-dimensions questionnaire (EQ-5D) and EQ VAS scores, and 
Table 1. Demographics, treatment profiles, and disease activity at enrollment for patients with multidomain vs single-domain PsA disease presentations.

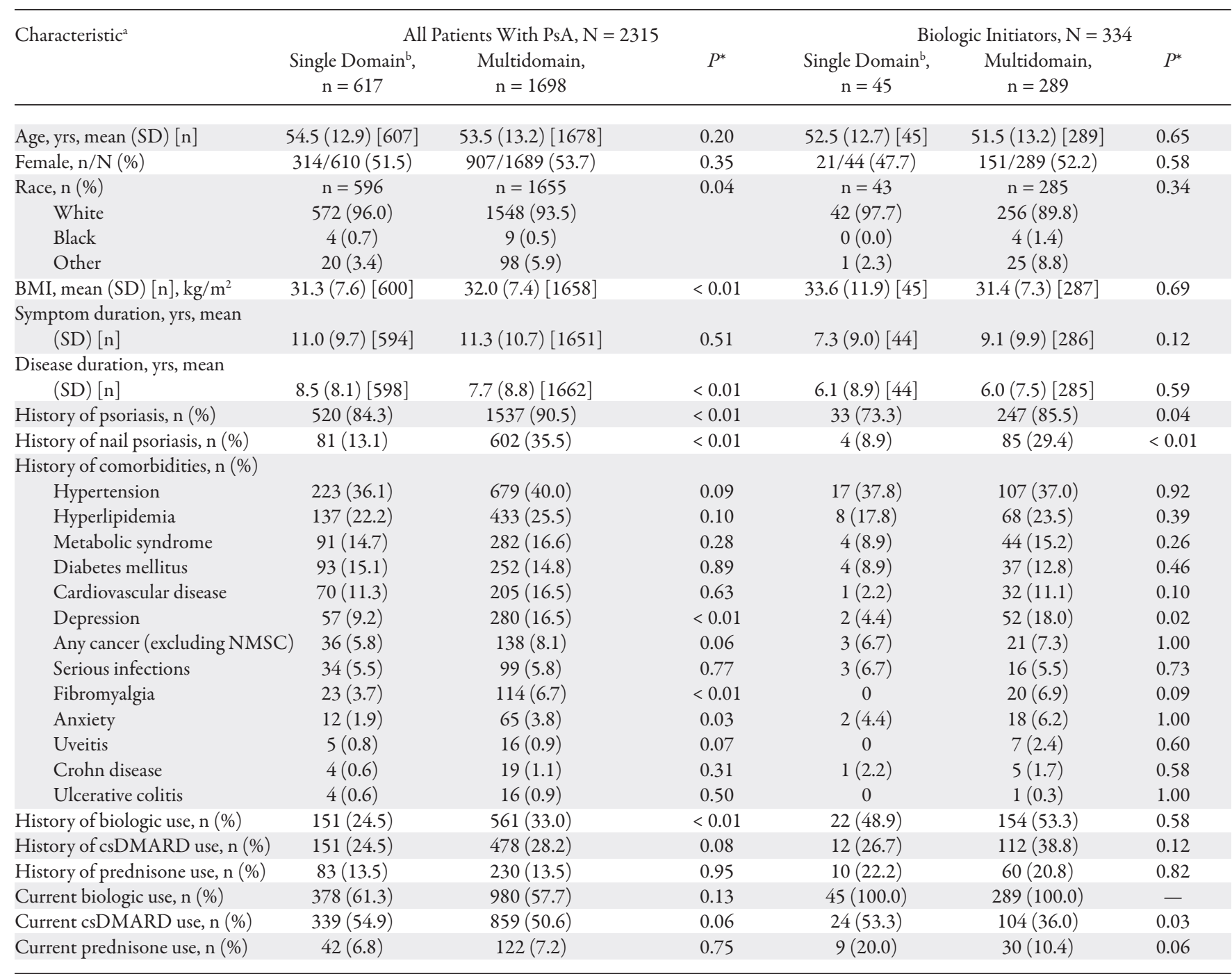

${ }^{a}$ All values were calculated based on available data. For continuous variables, [n] represents the number of patients with data available. ${ }^{b}$ Single-domain disease presentations for PsA overall $(\mathrm{N}=617)$ included skin disease $(53.8 \%)$, peripheral arthritis $(29.0 \%)$, nail psoriasis $(10.9 \%)$, axial disease (3.4\%), enthesitis (1.8\%), and dactylitis (1.1\%). Single-domain disease presentations for biologic initiators $(\mathrm{N}=45)$ included peripheral arthritis $(46.7 \%)$, skin disease $(35.6 \%)$, axial disease (6.7\%), nail psoriasis (4.4\%), enthesitis (4.4\%), and dactylitis $(2.2 \%) .{ }^{*}$ Wilcoxon rank-sum test or $t$-test for continuous variables and chi-square or Fisher exact test for categorical variables. csDMARD: conventional synthetic disease-modifying antirheumatic drug; NMSC: nonmelanoma skin cancer; PsA: psoriatic arthritis.

work and activity impairment as assessed by the WPAI questionnaire, respectively, than patients with single-domain presentations (Figure 3).

Unadjusted and adjusted associations of single-domain vs multidomain presentations with disease activity, QOL, and WPAI. In univariable linear models, there was an overall association between the presence of a multidomain presentation and significantly worse patient and physician global assessment of disease, patient-reported pain and fatigue, HAQ-DI and EQ-5D scores, and work productivity and activity at enrollment (all $P<0.05$; data not shown). These associations remained significant after adjusting for age, sex, race, BMI, disease duration, current and prior biologic, csDMARD, and prednisone use (Figure 4). The presence of a multidomain disease presentation was associated with an increased value for all evaluated variables compared with single-domain disease presentations.

\section{DISCUSSION}

Using real-world data, our results illustrate the heterogeneity and complexity of PsA. Nearly two-thirds (64.9\%) of the patients with PsA enrolled in the Corrona PsA/SpA Registry had multidomain disease presentations. Approximately one-tenth of patients $(11.5 \%)$ had no active disease features at time of enrollment; these patients could have been well controlled with treatment and not have had any active disease manifestations at the time of enrollment. Further, a multidomain presentation was 
Table 2. Disease activity at enrollment for patients with multidomain vs single-domain PsA disease presentations.

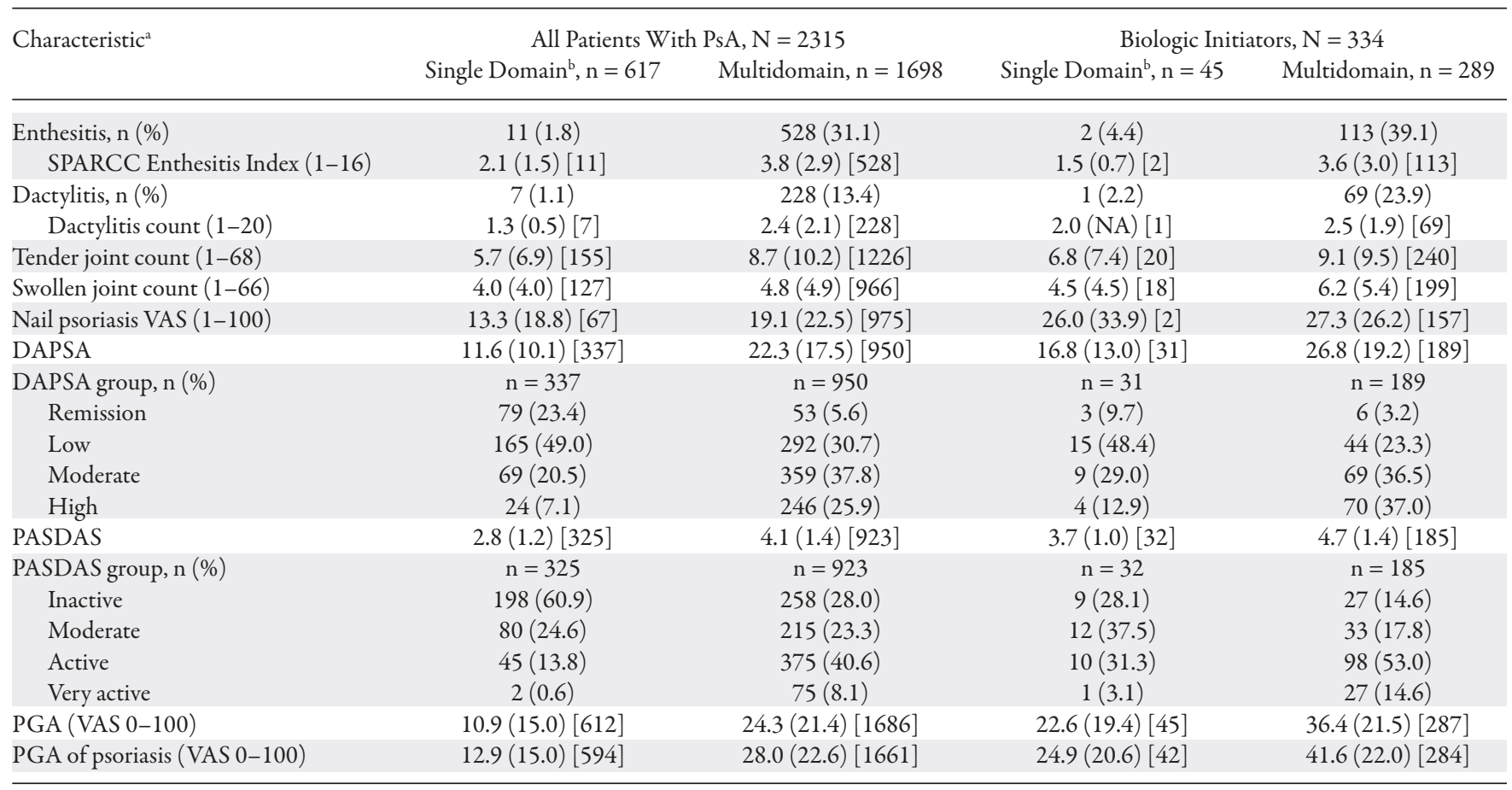

${ }^{a}$ All values were calculated based on available data and are presented as mean (SD) [n] unless otherwise stated; [n] represents the number of patients with data available. ${ }^{\mathrm{b}}$ Single-domain disease presentations for PsA overall $(\mathrm{N}=617)$ included skin disease $(53.8 \%)$, peripheral arthritis $(29.0 \%)$, nail psoriasis $(10.9 \%)$, axial disease (3.4\%), enthesitis (1.8\%), and dactylitis (1.1\%). Single-domain disease presentations for biologic initiators $(\mathrm{N}=45)$ included peripheral arthritis (46.7\%), skin disease (35.6\%), axial disease (6.7\%), nail psoriasis (4.4\%), enthesitis (4.4\%), and dactylitis (2.2\%). DAPSA: Disease Activity in PSoriatic Arthritis; NA: not available; PASDAS: Psoriatic Arthritis Disease Activity Score; PGA: physician global assessment; PsA: psoriatic arthritis; SPARCC: Spondyloarthritis Research Consortium of Canada; VAS: visual analog scale.

associated with worse disease activity, QOL, and work productivity measures compared with single-domain disease presentations. We also characterized disease presentations among 354 patients who initiated a biologic at the time of enrollment. Biologic initiators may be more reflective of patients with active disease because they had a higher prevalence of multidomain disease presentations at enrollment (81.6\%) than did the overall population of patients with PsA in this study. This analysis provides a unique view of the effect of single-domain vs multidomain PsA presentations from a broad geographic distribution across the USA, both at the time of registry enrollment and at initiation of a biologic therapy. These results highlight the wide spectrum of disease presentations among patients with PsA. Evaluation of the active disease domains is important for the development of an effective disease management plan.

The heterogeneity of PsA can complicate diagnosis, evaluation, and management of the disease ${ }^{12}$. Prior real-world studies have focused on characterizing patients who presented with a single active domain or 2 affected domains instead of reporting multiple disease domain presentations in individual patients with PsA ${ }^{13,14,17}$. Associations between individual single-domain presentations and greater overall disease burden and poorer QOL were previously reported ${ }^{13,14,17}$. Additionally, several studies have indicated a close link between nail psoriasis, dactylitis, and enthesitis ${ }^{18,19}$, and in other studies, presence of
PA predicted the development of erosive and deforming disease over time in prospective studies involving patients with $\mathrm{Ps}_{\mathrm{S}}{ }^{20,21}$. Taken together, these studies indicate that each of these singular core domains may have meaning for long-term outcomes. While these are important studies, ours adds to the literature the comparison of multidomain vs single-domain presentations and demonstrates that a multidomain presentation is associated with worse disease activity, QOL, and work productivity measures.

The goals of therapy for all patients with PsA include the achievement of the lowest possible level of disease activity in all disease domains, optimization of patient functional status, improvement in QOL, prevention of structural damage to the greatest extent possible, and avoidance or minimization of complications, both from untreated active disease and from therapy ${ }^{7}$. Treatment may differ depending on the PsA domains affected ${ }^{7,8,9}$. Current clinical trials focus on measures of PA as the primary outcome measure, although many have included measures of skin disease as key secondary outcome measures ${ }^{22-30}$. Most available agents also effectively treat enthesitis and dactylitis in patients with $\operatorname{PsA}^{24,25,27,29,31-38}$. Some therapies have also demonstrated efficacy in improving nail symptoms $s^{39,40,41,42,43,44}$. To date, only secukinumab has been evaluated in a large phase IIIb study in patients with axial involvement in PsA ${ }^{45}$, although in general, the tumor necrosis factor inhibitors and interleukin $17 \mathrm{~A}$ inhibitors are effective in treating ankylosing spondylitis 
A

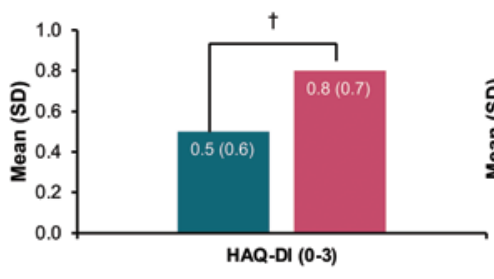

- Single domain $(n=586) \quad$ = Multidomain $(n=1600)$
Physical Function and Quality of Life*
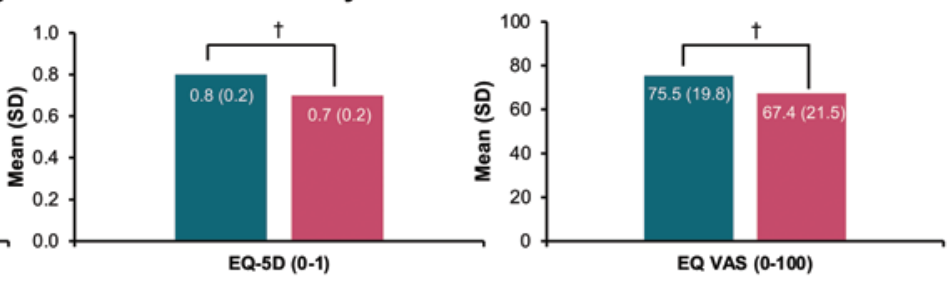

$=$ Single domain $(n=579) \quad=$ Multidomain $(n=1592) \quad=$ Single domain $(n=606) \quad=$ Multidomain $(n=1667)$

B

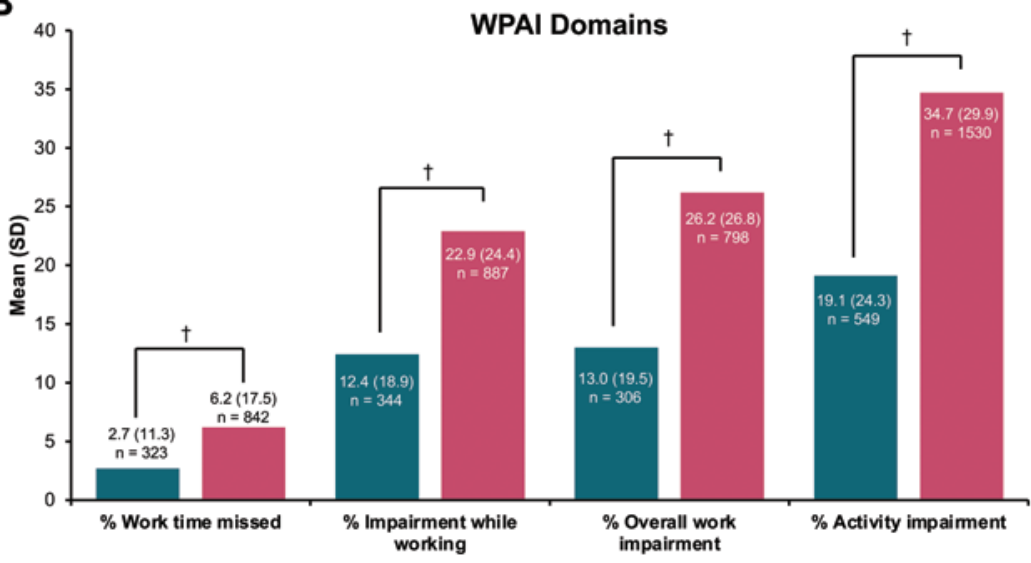

= Single domain (current employment $=381 / 595[64.0 \%])=$ Multidomain (current employment $=987 / 1646[60.0 \%]$ )

Figure 3. Overall (A) physical function and quality of life and (B) WPAI at enrollment for patients with multidomain vs single-domain PsA disease presentations. ${ }^{*}$ For HAQ-DI, higher scores indicate worse physical function. For EQ-5D and EQ VAS, lower scores indicate worse health status. $\dagger P<0.05$. EQ-5D: EuroQol 5-dimensions questionnaire; EQ VAS: EuroQol visual analog scale; HAQ-DI: Health Assessment Questionnaire-Disability Index; PsA: psoriatic arthritis; WPAI: Work Productivity and Activity Impairment.

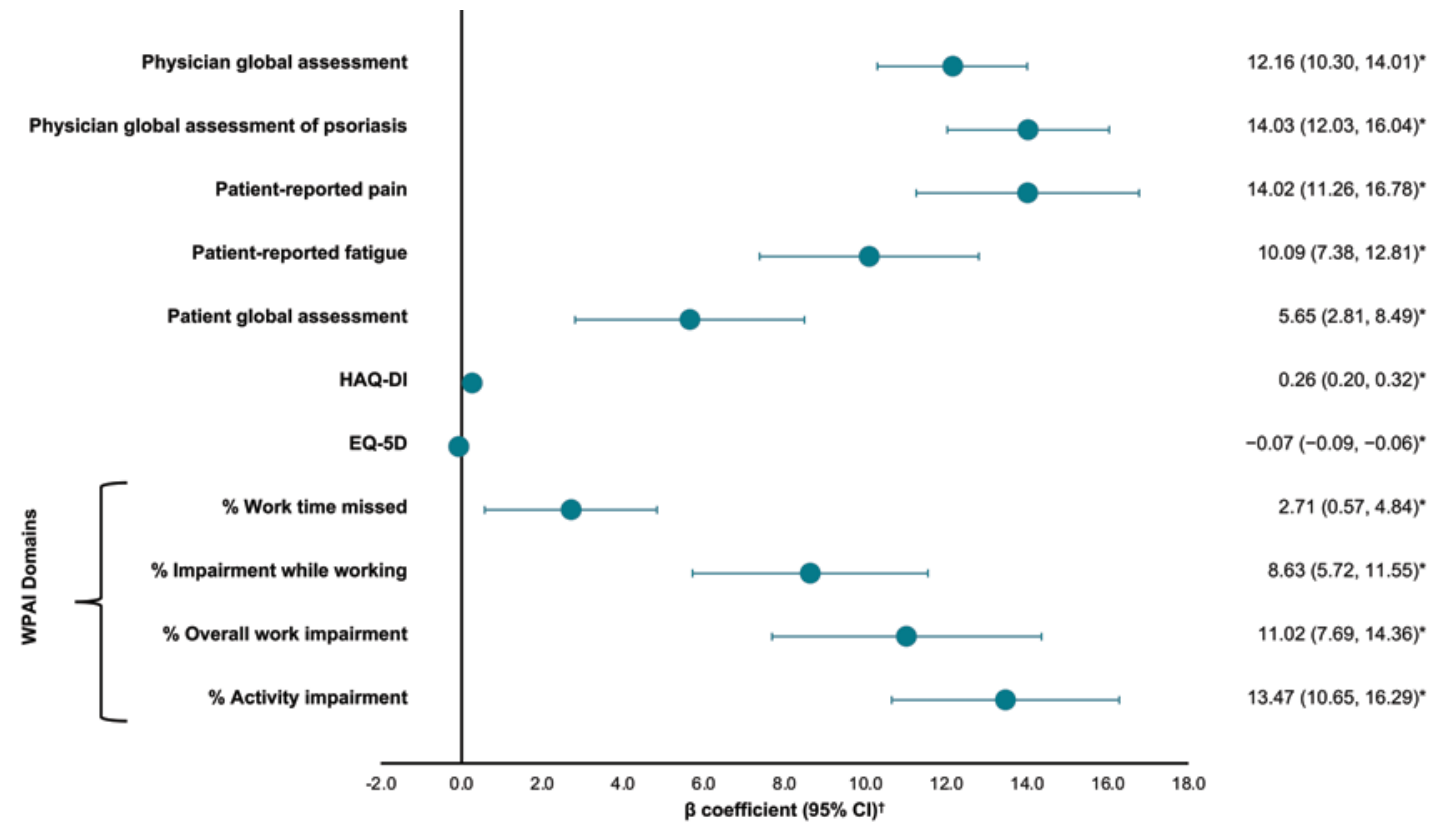

Figure 4. Multidomain vs single-domain effect on outcomes. Multivariable regression coefficients estimating the association of presence of multidomain presentations with selected PsA disease activity, quality of life, and work productivity and activity measures relative to single-domain presentations in patients with PsA. ${ }^{*} P<0.05 .{ }^{\dagger}$ Analyzed using multivariable regression coefficients adjusted for age, sex, race, BMI, disease duration, and current and prior biologic, csDMARD, and prednisone use. csDMARD: conventional synthetic disease-modifying antirheumatic drug; EQ-5D: EuroQol 5-dimensions questionnaire; HAQ-DI: Health Assessment Questionnaire-Disability Index; PsA: psoriatic arthritis; WPAI: Work Productivity and Activity Impairment. 
and are assumed to work in axial PsA as well. The optimal therapy selection is based on the domains involved and the severity of each domain ${ }^{46}$.

Some study limitations should be noted. Because the data source was a US registry in which clinician investigators enroll their patients, results may not be generalizable to all patients with PsA. Domains were physician-reported and may not reflect all PsA presentations experienced by patients. Because the Corrona registry examines patients in the course of routine clinical practice, data on domain presentation in patients who were receiving treatment may be underreported. Biologic initiators likely represent patients with an inadequate response to their previous treatment; because these patients were starting a new biologic at the time of enrollment, assessment of disease activity may not have been as confounded as in those patients who were already being treated at the time of enrollment, which may provide a more accurate reflection of the prevalence of disease domains. This was a descriptive analysis; therefore, certain factors such as treatment may not be accounted for, which may lead to the underrepresentation of the prevalence of domain presentations.

In summary, this study highlights the heterogeneity of PsA and demonstrates that the majority of patients with PsA in a US real-world setting presented with multiple active disease domains. These multidomain presentations are associated with increased clinical burden, including worse disease activity, QOL, and work productivity measures. Future studies can build on these results to identify clusters of domains that may affect response to individual therapies. As a first step, however, increased physician awareness of the heterogeneity of disease presentations among patients with PsA is important for optimizing disease management.

\section{ACKNOWLEDGMENT}

Support for third-party writing assistance for this manuscript, furnished by Kheng Bekdache, PhD, of Health Interactions Inc., was provided by Novartis Pharmaceuticals Corporation, East Hanover, NJ.

\section{ONLINE SUPPLEMENT}

Supplementary material accompanies the online version of this article.

\section{REFERENCES}

1. Gladman DD. Clinical features and diagnostic considerations in psoriatic arthritis. Rheum Dis Clin North Am 2015;41:569-79.

2. Kirkham B, de Vlam K, Li W, Boggs R, Mallbris L, Nab HW, et al. Early treatment of psoriatic arthritis is associated with improved patient-reported outcomes: findings from the etanercept PRESTA trial. Clin Exp Rheumatol 2015;33:11-9.

3. Orbai AM, de Wit M, Mease P, Shea JA, Gossec L, Leung YY, et al. International patient and physician consensus on a psoriatic arthritis core outcome set for clinical trials. Ann Rheum Dis 2017;76:673-80.

4. Ogdie A, Weiss P. The epidemiology of psoriatic arthritis. Rheum Dis Clin North Am 2015;41:545-68.

5. Gelfand JM, Gladman DD, Mease PJ, Smith N, Margolis DJ, Nijsten T, et al. Epidemiology of psoriatic arthritis in the population of the United States. J Am Acad Dermatol 2005;53:573.

6. Alinaghi F, Calov M, Kristensen LE, Gladman DD, Coates LC, Jullien D, et al. Prevalence of psoriatic arthritis in patients with psoriasis: a systematic review and meta-analysis of observational and clinical studies. J Am Acad Dermatol 2019;80:251-65.
7. Coates LC, Kavanaugh A, Mease PJ, Soriano ER, Laura Acosta-Felquer M, Armstrong AW, et al. Group for Research and Assessment of Psoriasis and Psoriatic Arthritis 2015 treatment recommendations for psoriatic arthritis. Arthritis Rheum 2016;68:1060-71.

8. Gossec L, Baraliakos X, Kerschbaumer A, de Wit M, McInnes I, Dougados M, et al. EULAR recommendations for the management of psoriatic arthritis with pharmacological therapies: 2019 update. Ann Rheum Dis 2020;79:700-12.

9. Singh JA, Guyatt G, Ogdie A, Gladman DD, Deal C, Deodhar A, et al. Special article: 2018 American College of Rheumatology/ National Psoriasis Foundation guideline for the treatment of psoriatic arthritis. Arthritis Care Res 2019;71:2-29.

10. Karreman MC, Weel AEAM, van der Ven M, Vis M, Tchetverikov I, Nijsten TEC, et al. Performance of screening tools for psoriatic arthritis: a cross-sectional study in primary care. Rheumatology 2017;56:597-602.

11. Mease PJ, Coates LC. Considerations for the definition of remission criteria in psoriatic arthritis. Semin Arthritis Rheum 2018; 47:786-96.

12. Mease PJ. Psoriatic arthritis: update on pathophysiology, assessment and management. Ann Rheum Dis 2011;70 Suppl 1:i77-84.

13. Mease PJ, Karki C, Palmer JB, Etzel CJ, Kavanaugh A, Ritchlin CT, et al. Clinical characteristics, disease activity, and patient-reported outcomes in psoriatic arthritis patients with dactylitis or enthesitis: results from the Corrona Psoriatic Arthritis/Spondyloarthritis Registry. Arthritis Care Res 2017;69:1692-9.

14. Mease PJ, Palmer JB, Liu M, Kavanaugh A, Pandurengan R, Ritchlin $\mathrm{CT}$, et al. Influence of axial involvement on clinical characteristics of psoriatic arthritis: analysis from the Corrona Psoriatic Arthritis/ Spondyloarthritis Registry. J Rheumatol 2018;45:1389-96.

15. Taylor W, Gladman D, Helliwell P, Marchesoni A, Mease P, Mielants $\mathrm{H}$; CASPAR Study Group. Classification criteria for psoriatic arthritis: development of new criteria from a large international study. Arthritis Rheum 2006;54:2665-73.

16. StataCorp. Stata Statistical Software Relsease 15. College Station, TX: StataCorp, LLC, 2017.

17. Tillett W, Hartz S, Moon R, Lobosco S, Milligan G, Birt J. The economic burden of skin symptoms in psoriatic arthritis. Value Health 2018;S194:PMS22.

18. Lai TL, Pang HT, Cheuk YY, Yip ML. Psoriatic nail involvement and its relationship with distal interphalangeal joint disease. Clin Rheumatol 2016;35:2031-7.

19. Raposo I, Torres T. Nail psoriasis as a predictor of the development of psoriatic arthritis. Actas Dermosifiliogr 2015;106:452-7.

20. McHugh NJ, Balachrishnan C, Jones SM. Progression of peripheral joint disease in psoriatic arthritis: a 5-yr prospective study. Rheumatology 2003;42:778-83.

21. Queiro-Silva R, Torre-Alonso JC, Tinture-Eguren T, Lopez-Lagunas I. A polyarticular onset predicts erosive and deforming disease in psoriatic arthritis. Ann Rheum Dis 2003;62:68-70.

22. Mease PJ, Kivitz AJ, Burch FX, Siegel EL, Cohen SB, Ory P, et al. Etanercept treatment of psoriatic arthritis: safety, efficacy, and effect on disease progression. Arthritis Rheum 2004;50:2264-72.

23. Mease PJ, van der Heijde D, Ritchlin CT, Okada M, Cuchacovich RS, Shuler CL, et al; SPIRIT-P1 Study Group. Ixekizumab, an interleukin-17a specific monoclonal antibody, for the treatment of biologic-naive patients with active psoriatic arthritis: results from the 24-week randomised, double-blind, placebo-controlled and active (adalimumab)-controlled period of the phase III trial SPIRIT-P1. Ann Rheum Dis 2017;76:79-87.

24. Antoni C, Krueger GG, de Vlam K, Birbara C, Beutler A, Guzzo C, et al; IMPACT 2 Trial Investigators. Infliximab improves signs and symptoms of psoriatic arthritis: results of the IMPACT 2 trial. Ann Rheum Dis 2005;64:1150-7. 
25. Mease PJ, Fleischmann R, Deodhar AA, Wollenhaupt J, Khraishi M, Kielar D, et al. Effect of certolizumab pegol on signs and symptoms in patients with psoriatic arthritis: 24-week results of a phase 3 double-blind randomised placebo-controlled study (RAPID-PsA). Ann Rheum Dis 2014;73:48-55.

26. Kavanaugh A, Husni ME, Harrison DD, Kim L, Lo KH, Leu JH, et al. Safety and efficacy of intravenous golimumab in patients with active psoriatic arthritis: results through week twenty-four of the GO-VIBRANT study. Arthritis Rheum 2017;69:2151-61.

27. Mease P, van der Heijde D, Landewé R, Mpofu S, Rahman P, Tahir $\mathrm{H}$, et al. Secukinumab improves active psoriatic arthritis symptoms and inhibits radiographic progression: primary results from the randomised, double-blind, phase III FUTURE 5 study. Ann Rheum Dis 2018;77:890-7.

28. Nash P, Kirkham B, Okada M, Rahman P, Combe B, Burmester GR, et al; SPIRIT-P2 Study Group. Ixekizumab for the treatment of patients with active psoriatic arthritis and an inadequate response to tumour necrosis factor inhibitors: results from the 24-week randomised, double-blind, placebo-controlled period of the SPIRIT-P2 phase III trial. Lancet 2017;389:2317-27.

29. McInnes IB, Kavanaugh A, Gottlieb AB, Puig L, Rahman P, Ritchlin C, et al; PSUMMIT 1 Study Group. Efficacy and safety of ustekinumab in patients with active psoriatic arthritis: 1 year results of the phase 3, multicentre, double-blind, placebo-controlled PSUMMIT 1 trial. Lancet 2013;382:780-9.

30. Mease PJ, Gottlieb AB, van der Heijde D, FitzGerald O, Johnsen A, Nys $\mathrm{M}$, et al. Efficacy and safety of abatacept, a T-cell modulator, in a randomised, double-blind, placebo-controlled, phase III study in psoriatic arthritis. Ann Rheum Dis 2017;76:1550-8.

31. Antoni CE, Kavanaugh A, Kirkham B, Tutuncu Z, Burmester GR, Schneider U, et al. Sustained benefits of infliximab therapy for dermatologic and articular manifestations of psoriatic arthritis: results from the infliximab multinational psoriatic arthritis controlled trial (IMPACT). Arthritis Rheum 2005;52:1227-36.

32. Ritchlin C, Rahman P, Kavanaugh A, McInnes IB, Puig L, Li S, et al; PSUMMIT 2 Study Group. Efficacy and safety of the anti-IL-12/23 p40 monoclonal antibody, ustekinumab, in patients with active psoriatic arthritis despite conventional non-biological and biological anti-tumour necrosis factor therapy: 6-month and 1 -year results of the phase 3 , multicentre, double-blind, placebo-controlled, randomised PSUMMIT 2 trial. Ann Rheum Dis 2014;73:990-9.

33. Mease PJ, McInnes IB, Kirkham B, Kavanaugh A, Rahman P, van der Heijde D, et al; FUTURE 1 Study Group. Secukinumab inhibition of interleukin-17A in patients with psoriatic arthritis. N Engl J Med 2015;373:1329-39.

34. Nash P, Mease PJ, McInnes IB, Rahman P, Ritchlin CT, Blanco R, et al; FUTURE 3 study group. Efficacy and safety of secukinumab administration by autoinjector in patients with psoriatic arthritis: results from a randomized, placebo-controlled trial (FUTURE 3). Arthritis Res Ther 2018;20:47.

35. Deodhar A, Gottlieb AB, Boehncke WH, Dong B, Wang Y, Zhuang Y, et al; CNTO1959PSA2001 Study Group. Efficacy and safety of guselkumab in patients with active psoriatic arthritis: a randomised, double-blind, placebo-controlled, phase 2 study. Lancet 2018;391:2213-24.

36. Sterry W, Ortonne JP, Kirkham B, Brocq O, Robertson D, Pedersen $\mathrm{RD}$, et al. Comparison of two etanercept regimens for treatment of psoriasis and psoriatic arthritis: PRESTA randomised double blind multicentre trial. BMJ 2010;340:c147.

37. Gladman DD, ACCLAIM Study Investigators, Sampalis JS, Illouz $\mathrm{O}$, Guerette B. Responses to adalimumab in patients with active psoriatic arthritis who have not adequately responded to prior therapy: effectiveness and safety results from an open-label study. J Rheumatol 2010;37:1898-906.

38. Gladman DD, Orbai AM, Klitz U, Wei JC, Gallo G, Birt J, et al. Ixekizumab and complete resolution of enthesitis and dactylitis: integrated analysis of two phase 3 randomized trials in psoriatic arthritis. Arthritis Res Ther 2019;21:38.

39. Elewski BE, Okun MM, Papp K, Baker CS, Crowley JJ, Guillet G, et al. Adalimumab for nail psoriasis: efficacy and safety from the first 26 weeks of a phase 3, randomized, placebo-controlled trial. J Am Acad Dermatol 2018;78:90-9.

40. Reich K, Sullivan J, Arenberger P, Mrowietz U, Jazayeri S, Augustin $\mathrm{M}$, et al. Effect of secukinumab on the clinical activity and disease burden of nail psoriasis: 32-week results from the randomized placebo-controlled TRANSFIGURE trial. Br J Dermatol 2019;181:954-66.

41. Gordon KB, Colombel JF, Hardin DS. Phase 3 trials of ixekizumab in moderate-to-severe plaque psoriasis. N Engl J Med 2016;375:2102.

42. van de Kerkhof P, Guenther L, Gottlieb AB, Sebastian M, Wu JJ, Foley $\mathrm{P}$, et al. Ixekizumab treatment improves fingernail psoriasis in patients with moderate-to-severe psoriasis: results from the randomized, controlled and open-label phases of UNCOVER-3. J Eur Acad Dermatol Venereol 2017;31:477-82.

43. Blauvelt A, Papp KA, Griffiths CE, Randazzo B, Wasfi Y, Shen YK, et al. Efficacy and safety of guselkumab, an anti-interleukin-23 monoclonal antibody, compared with adalimumab for the continuous treatment of patients with moderate to severe psoriasis: results from the phase III, double-blinded, placebo- and active comparator-controlled VOYAGE 1 trial. J Am Acad Dermatol 2017;76:405-17.

44. Reich K, Gooderham M, Bewley A, Green L, Soung J, Petric R, et al. Safety and efficacy of apremilast through 104 weeks in patients with moderate to severe psoriasis who continued on apremilast or switched from etanercept treatment: findings from the LIBERATE study. J Eur Acad Dermatol Venereol 2018;32:397-402.

45. Baraliakos X, Coates LC, Gossec L, Sławomir J, Mera Varela A, Schulz B, et al. Secukinumab improves axial manifestations in patients with psoriatic arthritis and inadequate response to NSAIDs: primary analysis of the MAXIMISE trial. Ann Rheum Dis 2019;78 Suppl 2:195-6.

46. Coates LC, Gossec L, Ramiro S, Mease P, van der Heijde D, Smolen JS, et al. New GRAPPA and EULAR recommendations for the management of psoriatic arthritis. Rheumatology 2017;56:1251-3. 